\title{
OPTICAl MEASUREMENT OF ASIAN DUST OVER DAEJEON City IN 2016 BY DEPOLARIZATION LIDAR IN AD-NETWORK Park Chan Bong $^{1^{*}}$, Atsushi Shimizu ${ }^{2}$, Nobuo Sugimoto ${ }^{2}$
}

${ }^{I}$ Dept. of Electronic Engineering, Mokwon University, 88 Doan-bukro, Seo-Gu, Dae-jeon, Korea, cbpark@mokwon.ac.kr

${ }^{2}$ National Institute for Environmental Studies, 16-2, Onogawa, Tsukuba, Ibaraki, 305-8506, Japan, nsugimot@nies.go.kr

\begin{abstract}
Long-term sustained heavy Asian Dust below 3 $\mathrm{km}$ was measured in the period of April 22-26 by 2 -wavelengths depolarization lidar system. As the comparison results of Daejeon station with other stations in the AD-Net, similarly formed Asian dust had been measured at Nigata, Toyama, Matsue, and Sendai. The route of the dust was examined by HYSPLIT. More than $80 \mu \mathrm{g} / \mathrm{m}^{3}$ mass concentrations derived from the lidar measurements were compared with Air-Korea PM10 data.
\end{abstract}

\section{INTRODUCTION}

In every spring season, a huge amount of Asian dust generated in inner China, Mongolia and Taklimakan areas are transported and widely dispersed to East Asia region including Korean peninsula and Japan. As one of the major continental aerosols, the Asian dust caused great effects on radiation budget and climate changes, depending on their concentration, composition, and height distribution in the atmosphere. Optical properties, spatial distribution, and long-range transportation mechanism of the dust have been studied using ground based measurement profiles, satellite images and numerical modeling. Among them, lidar measurements method provides a useful and simple tool that can directly measure the vertical profiles of the aerosols and dust up to the upper troposphere with higher spatial and temporal resolutions [1][2]. Many studies about the origins and transportation route of the dust in free troposphere have considered several dominant sources of the Asian dust such as Mongolia, Taklimakan, and Loess area in east China. Recently, to know the contributions from unknown desert sources and understanding of transportation route, many lidar stations have been constructed in the East Asia and collaboration measurements have been performed. Since 2001, the Asian dust Network (AD-Net) has been expanding the stations. At present, more than 20 lidar stations in Japan, Korea, and China are located in the Network [3]. For collaboration measurements, Daejeon station in Korea has been involved in the Network since 2010. Because of the dust frequently mixed with pollutant gases or water vapor during their transportation, the optical characteristics of the dust are also changed. A polarization lidar technique is very useful tool to distinguish the dust aerosol, spherical aerosols, and clouds according to their shapes [3]. However, uncertainties of the dust aerosols (distribution, amount, characteristics) are still remained. To analyze the contribution of the dust and the spherical aerosol on the calculation of the backscattering coefficient, method using depolarization ratio was developed and published.

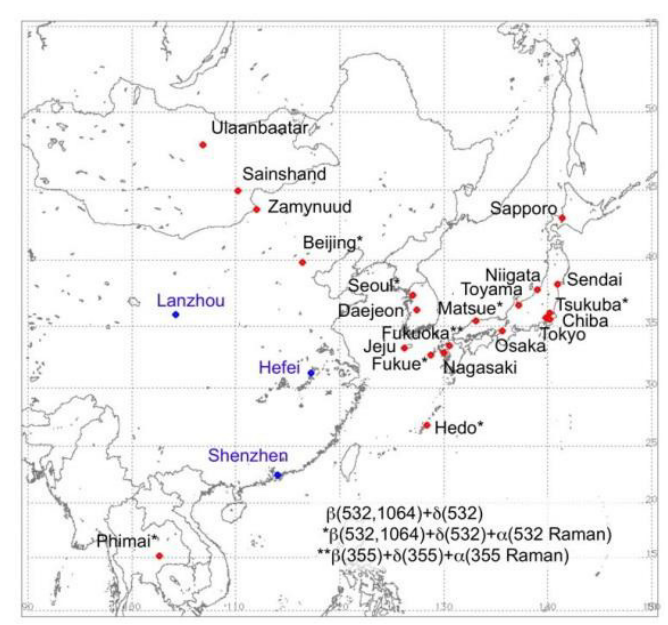

Figure 1 Stations in the AD-Net

\section{LIDAR SYSTEM}

The Lidar system in Daejeon station as a one compact package unit consisted of transmitter and receiver modules. The lidar system use the 
second-harmonic Nd:YAG laser and $300 \mathrm{~mm}$ diameter telescope. The transmitting output energy at each wavelength of Nd:YAG laser is 65 $\mathrm{mJ}$ at $532 \mathrm{~nm}, 190 \mathrm{~mJ}$ at $1064 \mathrm{~nm}$. The receiving system has Newtonian telescope with $30 \mathrm{~cm}$ diameter and four polarization channels that are 532(Vertical) /532 (Parallel) and 1064(Vertical) /1064(Parallel). PMT and APD detectors are allocated to the $532 \mathrm{~nm}$ and $1064 \mathrm{~nm}$ channels respectively. For the depolarization alignments, the polarizing beam splitter (PBS) is used only for the separate of the polarization (Vertical and Parallel of the receiving beam). Using the return signal at $532 \mathrm{~nm}$ and $1064 \mathrm{~nm}$ we calculate the aerosol backscattering coefficient using the Fernald method [4].

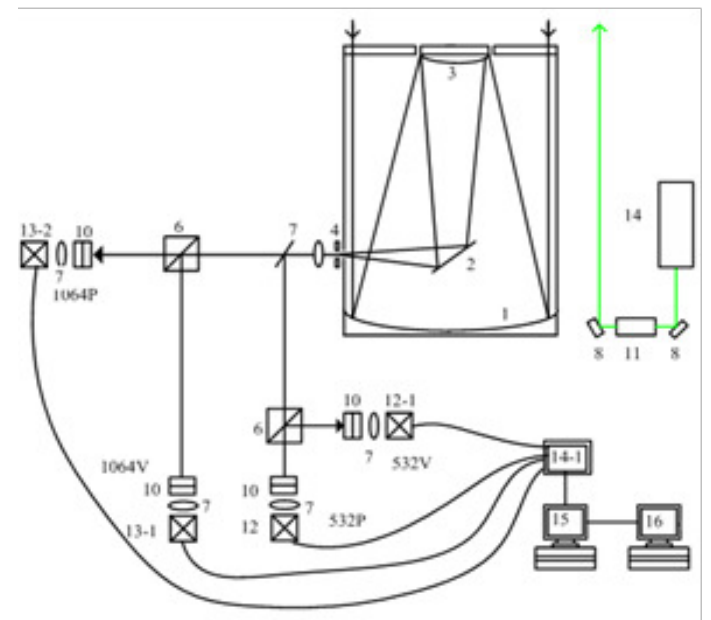

Figure 2 Block diagram of ACA Lidar system

(1. main mirror, 2. telescope reflection mirror, 3. secondary mirror, 4. Iris, 6. polarization 7. focusing lens, 8. transmitter reflection mirror, 10. interference filter, 11. beam expander, 12. PMT 13. APD, 14.ND:YAG laser, 14.1 Digital OSC, 15. PC1, 16. PC2)

At the first step in the calculation of, the value of $\beta_{a}\left(z_{b}\right)$ is given as the boundary value at the boundary altitude $\mathrm{z}_{\mathrm{b}}$. Usually, the a priori value of $0 \%-3 \%$ of the Rayleigh backscattering coefficient at the altitude of $6-10 \mathrm{~km}$ is used as the boundary $\beta_{\mathrm{a}}\left(\mathrm{z}_{\mathrm{b}}\right)$ value, and the boundary altitude $\mathrm{z}_{\mathrm{b}}$ and the extinction/backscatter ratio of aerosols $S_{a}$ are assumed to be constant with time and altitude. Figure 2 show a block diagram of the two wavelengths dual polarization lidar system and Table I is a specification of the lidar system.

Table 1 Specification of Lidar System

\section{Transmitter}

Laser : Surelite I-10

Max. output :470 mJ @1064 nm

220 mJ @532 nm

Beam div : $0.6 \mathrm{mrad}$

Repetition : $10 \mathrm{~Hz}$

SHG : type I for $1064 \mathrm{~nm}$ and $532 \mathrm{~nm}$

\section{Receiver}

Telescope : Newtonian type

1st mirror, $300 \mathrm{~mm}$

FOV, 0.3-6.4 $\mathrm{mrad}(1 \mathrm{mrad})$

Receiving channel : $1064 \mathrm{~nm} \mathrm{~V} \mathrm{and} 1064$ nm P

$532 \mathrm{~nm} \mathrm{~V}$ and $532 \mathrm{~nm} \mathrm{P}$

Detector : PMT , Hamamatsu-H6780

APD , Licel-APD-1.5

Data Acquisition : LeCroy-LT264, 4ch,

$350 \mathrm{MHz}, 1 \mathrm{GS} / \mathrm{sec}, 8$ bits

Operation mode : 5 min-on, 10 min-off

Range resolution : $6 \mathrm{~m}$

\section{MEASUREMENTS}

In a spring season in 2016, we measured very heavy dust layers in the lower troposphere by the lidar during a time of April 22th (06:00, UTC) April 26th (22:00, UTC) at Daejeon station in Korea. Figure 3 show Time-Height Indication (THI) plots of $532 \mathrm{~nm}$ backscatter coefficient (a), $1064 \mathrm{~nm}$ backscatter coefficient (b), depolarization ratio of $532 \mathrm{~nm}$ (c), and ratio of backscatter coefficient between $1064 \mathrm{~nm}$ and 532 $\mathrm{nm}$ (d). Higher backscatter coefficients and depolarization ratios measured at each wavelength of $532 \mathrm{~nm}$ and $1064 \mathrm{~nm}$ below $2 \mathrm{~km}$ were observed during that period. The maximum backscatter coefficient of $532 \mathrm{~nm}$ and $1064 \mathrm{~nm}$ 
showed over $1 \times 10^{-5}(/ \mathrm{m} / \mathrm{sr})$. The value of ratio of backscatter coefficient between
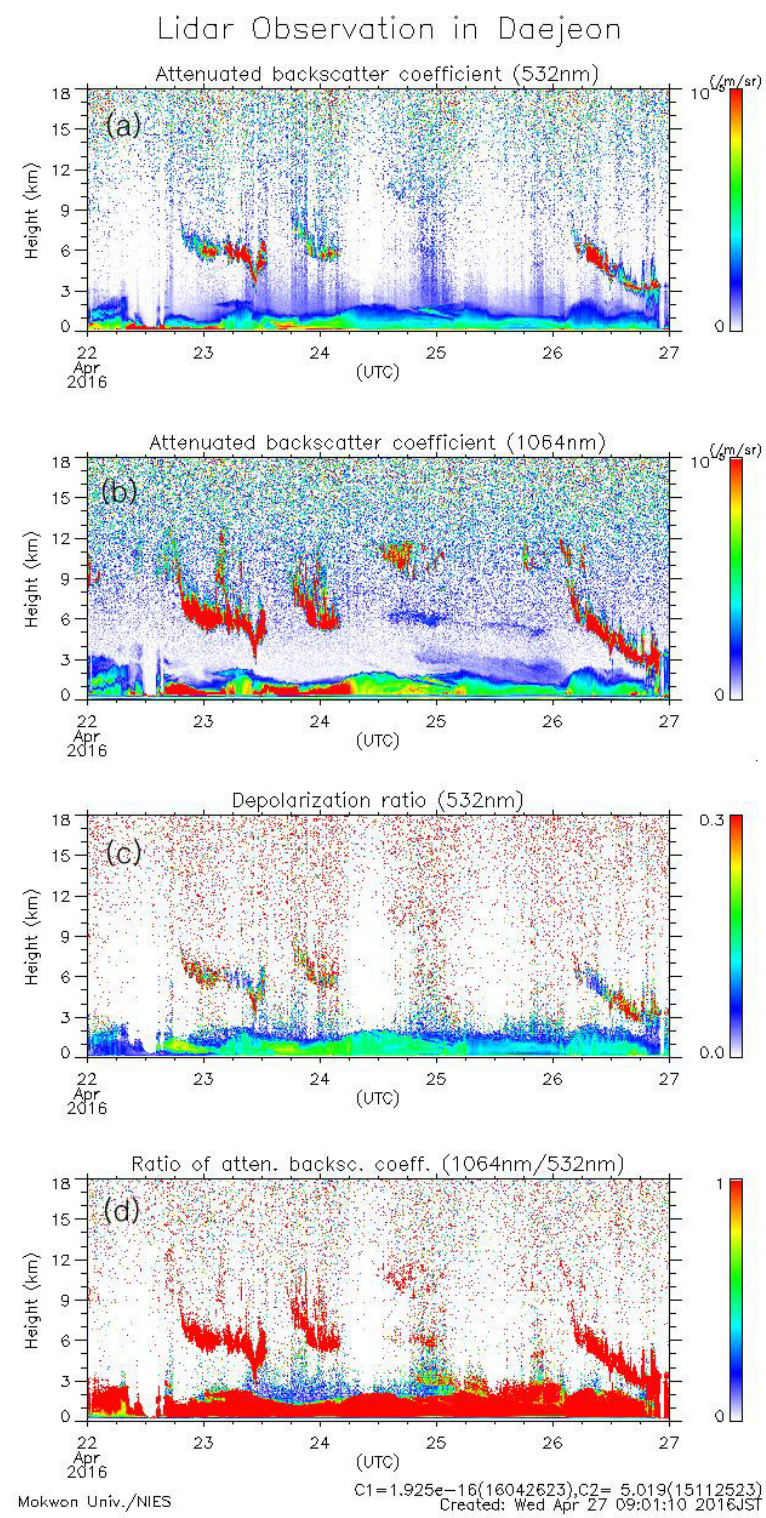

Figure $3 \mathrm{THI}$ plots of $532 \mathrm{~nm}$ backscatter coefficient (a), $1064 \mathrm{~nm}(\mathrm{~b}), 532 \mathrm{~nm}$ depolarization ratio(c), and ratio of backscatter coefficient between $1064 \mathrm{~nm}$ and $532 \mathrm{~nm}(d)$.

$1064 \mathrm{~nm}$ and $532 \mathrm{~nm}$ (d) dependent on particle size showed near 1 and indicate that larger particles were located in center of the dust layer. The maximum depolarization ration showed about $20 \sim 25 \%$ at $532 \mathrm{~nm}$.

\section{COMPARISON}

As the comparison results of Daejeon station with other stations in the AD-Net, similarly formed
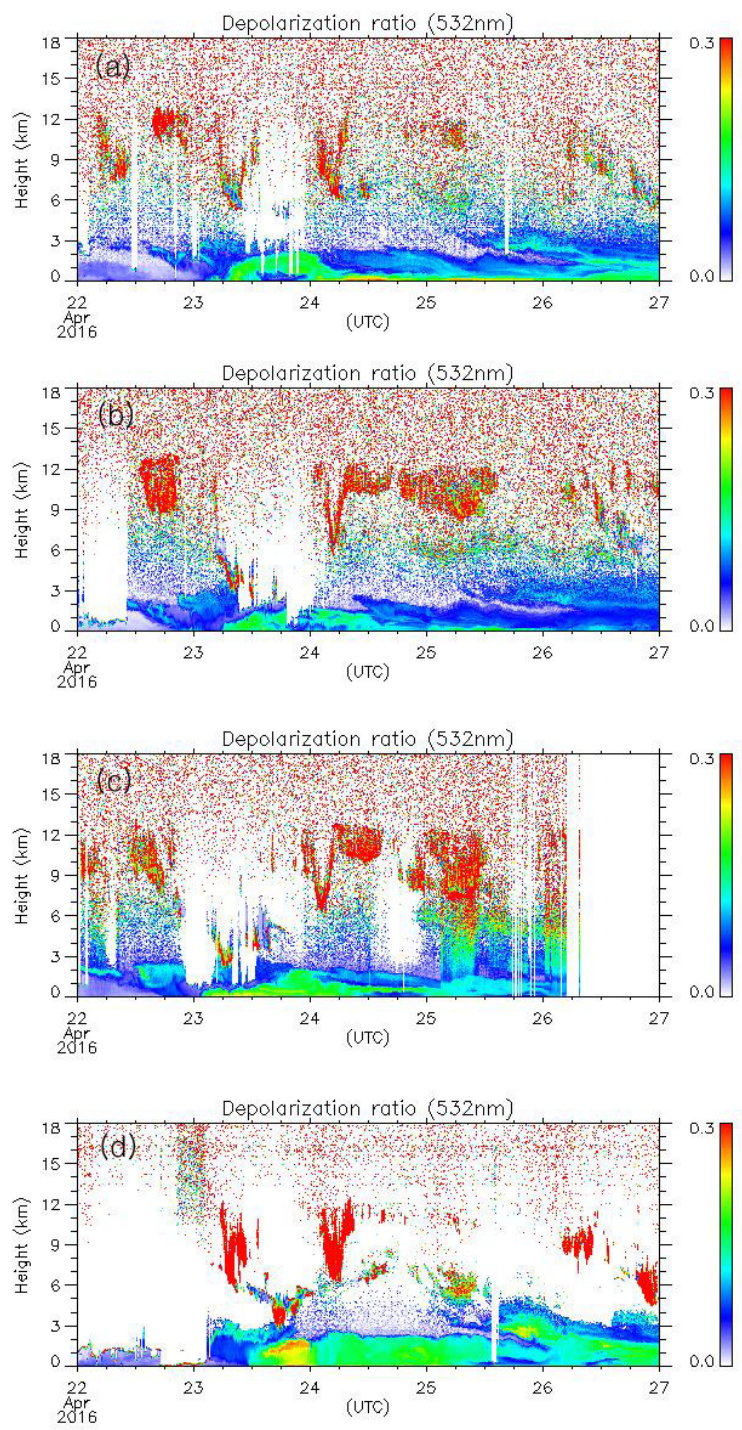

Figure 4 THI plots of $532 \mathrm{~nm}$ depolarization ratio measures at Nigata(a), Toyama(b), Matsue(c), and Sendai $(d)$.

Asian dust with 10 25\% depolarization ratio had been measured at Nigata, Toyama, Matsue, and Sendai in Japan during that period of April 23th April 26th. However, this kind of long-term continuously measured dust was not observed at other stations in Japan such as Fukue, Nagasaki, Osaka, Tsukuba, Tokyo, and Chiba. Figure 5 show the Time-Height Indication(THI) plots of 
depolarization ratio of $532 \mathrm{~nm}$ at Nigata (138.94E, $37.84 \mathrm{~N})$, Toyama(137.10E, $36.70 \mathrm{~N})$, Matsue (133.01E, 35.48N), and Sendai (140.83E, 38.26N). To know the transported route of the dust layer, backward and forward trajectory analysis from Daejeon station was performed. Figure 5 show the results of the backward and forward trajectory analysis. NOAA HYSPLIT MODEL using GDAS meteorological data was used for this Analysis [5]. The forward trajectory below $2 \mathrm{~km}$ over Daejeon station started on April 22, 06:00 with running time of $72 \mathrm{hrs}$. The result of this analysis clearly showed that the dust transported route passed Nigata, Toyama, and Matsue. The backward trajectory started from Sendai on April 22, 18:00 also showed the dust layer over passed Daejeon area.

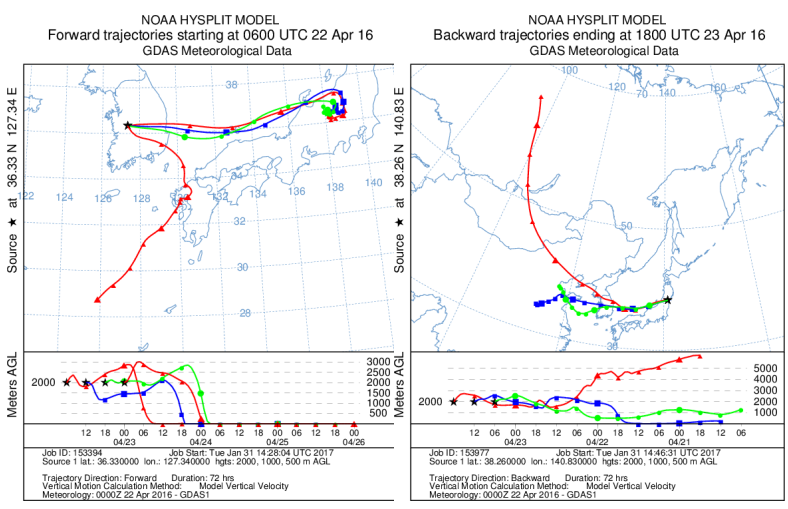

Figure 5 Forward Trajectory started from Daejeon station on April 22, 06:00 and Backward Trajectory started from Sendai station on April 22, 18:00.

The mass concentration of aerosol was calculated from averaged AOD values in PBL altitudes with mass conversion factor of $3.6 \pm 1.2 \mathrm{~m}^{2} \mathrm{~g}^{-1}$. Figure 6 show the mass concentration variation in April, 2016. More than $80 \mu \mathrm{g} / \mathrm{m}^{3}$ mass concentrations were observed during that period of Asian dust measurements. Its results was also coincides well with the report of PM10 by KMA in Korea.

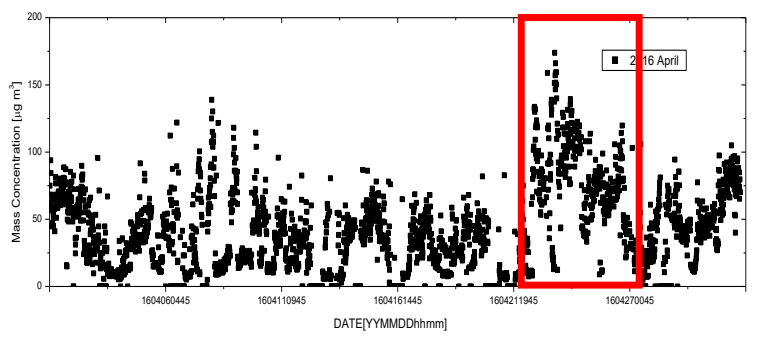

Figure 6 Mass concentration variations in April, 2016 derived from averaged $A O D$ value in PBL (red box shows the period of the Asian dust measurements).

\section{CONCLUSIONS}

The monitoring of Asian Dust has been performed with 2-wavelengths depolarization lidar in Daejeon station. Strong and long term sustained Asian dust had been measured during a period from April 22th to April 26th. The maximum backscatter coefficient over $10^{-5}(/ \mathrm{m} / \mathrm{sr})$ with depolarization ratio over $25 \%$ were observed. At the time period within a few days, similar dust events were measured consequently at Nigata, Toyama, Matsue, and Sendai in Japan. The backward and forward trajectory analysis by NOAA HYSPLIT Model showed coincidence with the results of lidar measurement in the station of AD-Net.

\section{ACKNOWLEDGEMENTS}

The research was supported by 'Software Convergence Technology Development Program', through the Ministry of Science, ICT and Future Planning (S0177-16-1059).

\section{References}

[1] Sugimoto N, A. Shimizu, I. Matsui, I. Uno, K Arao, X. Dong, S. Zhao, J. Zhou, and C. H. LEE, "Study of Dust Transport Using a Network of Continuously Operated Polarization Lidars", Water, Air, and Soil Pollution: Focus 5, (2005), pp. 145157.

[2] Liu X, Y. Cheng, Y. Zhang, J. Jung, N. Sugimoto, S.Y. Chang, Y. J. Kim, S. Fan, L. Zeng, "Influences of relative humidity and particle chemical composition on aerosol scattering properties during the 2006 PRD campaign", Atmospheric Environment, vol. 42, No. 7, (2008), pp. 1525-1536.

[3] Shimizu A, K Arao, T. Murayama, N. Kagawa, K. Aoki, A. Uchiyama, and A. Yamazaki, "Continuous observations of Asian dust and other aerosols by polarization lidars in China and Japan during ACE-Asia", Journal of Geophysical Research, vol. 109, (2004), pp. D19S17.

[4] Fernald F.G, "Analysis of atmospheric LIDAR observations: Some comments", Applied Optics, vol. 23, No. 5, (1984), pp. 652-653. 
[5] NOAA Air Resources Laboratory,

http://ready.arl.noaa.gov/ HYSPLIT .php 